\title{
Long-Term Toxicity Following 3D Conformal Radiation Therapy for Prostate Cancer on RTOG 9406, a Phase I/II Dose Escalation Study
}

\author{
Jeff M. Michalski, MD ${ }^{1}$, Kyounghwa Bae, $\mathrm{PhD}^{2}$, Mack Roach, $\mathrm{MD}^{3}$, Arnold M. Markoe, MD ${ }^{4}$, \\ Howard M. Sandler, MD ${ }^{5}$, Janice Ryu, MD ${ }^{6}$, Matthew B. Parliament, MD ${ }^{7}$, William Straube, \\ MS $^{8}$, Richard K Valicenti, MD ${ }^{9}$, and James D. Cox, MD ${ }^{10}$ \\ ${ }^{1}$ Radiation Oncology, Washington University Medical School, St. Louis, MO \\ 2 Department of Statistics, Radiation Therapy Oncology Group, Philadelphia, PA \\ ${ }^{3}$ Radiation Oncology, University of California-San Francisco, San Francisco, CA \\ ${ }^{4}$ Radiation Oncology, University Miami, Miami, FL \\ ${ }^{5}$ Radiation Oncology, University of Michigan, Ann Arbor, MI \\ ${ }^{6}$ Radiation Oncology, University of California-Davis, Davis, CA \\ ${ }^{7}$ Radiation Oncology, University of Alberta, Edmonton, AB, CAN \\ 8 Image-guided Therapy Center, St. Louis, MO \\ ${ }^{9}$ Radiation Oncology, Thomas Jefferson University, Philadelphia, PA \\ 10 Radiation Oncology, M.D. Anderson Cancer Center, Houston, TX
}

\begin{abstract}
Introduction and Objective-Update of late toxicity on RTOG 9406, a 3DCRT dose escalation trial for prostate cancer.

Methods-1084 men were registered to this phase I/II trial of 3DCRT (eligible patients $=1055$ ). Dose levels were as follows: Level I, 68.4 Gy; Level II, 73.8 Gy; Level III, 79.2 Gy; Level IV, 74 Gy; Level V, 78 Gy. Levels I-III received 1.8Gy/fraction and Levels IV-V 2.0Gy/fraction. Group I were treated to the prostate only, Group 2 to the prostate and SV with prostate boost, Group 3 to the prostate and SV. Median follow-up in surviving patients was $6.1 \mathrm{y}$ (level V) to $12.1 \mathrm{y}$ (level I).
\end{abstract}

Results-The incidences of RTOG grade $\geq 3$ gastrointestinal or genitourinary toxicity were $3 \%$, $4 \%, 6 \%, 7 \%$ and $9 \%$ in group 1 and $6 \%, 2 \%, 6 \%, 9 \%$, and $12 \%$ in group 2 at dose levels I, II, III, IV and $\mathrm{V}$, respectively. In group 1 , level $\mathrm{V}$ patients have higher probability of grade $\geq 2$ late GI or GU

Corresponding author: Jeff Michalski, M.D., Professor and Head, Department of Radiation Oncology, Washington University School of Medicine, 4921 Parkview Place, Campus box 8224, St. Louis, Missouri 63110, Tel\#: (314) 362-28566, Fax\#: (314) 747-9557, jmichalski@radonc.wustl.edu.

Conflict of Interest Statement: This work was supported by grants from the National Cancer Institute. Supported by Grants No. RTOG U10 CA21661, CCOP, and Stat U10CA32115 from the NCI No commercial products are described or endorsed by the authors. The authors have no relationship with organizations that would influence the results reported in this manuscript

Presented at Annual Meeting of the American Urological Association, May 19-24, 2007, Anaheim, California

Publisher's Disclaimer: This is a PDF file of an unedited manuscript that has been accepted for publication. As a service to our customers we are providing this early version of the manuscript. The manuscript will undergo copyediting, typesetting, and review of the resulting proof before it is published in its final citable form. Please note that during the production process errors may be discovered which could affect the content, and all legal disclaimers that apply to the journal pertain. 
toxicity compared to level I, II, and III (hazard ratio $(\mathrm{HR})=1.93, \mathrm{p}=0.0101 ; \mathrm{HR}=2.29, \mathrm{p}=0.0007$; $\mathrm{HR}=2.52, \mathrm{p}=0.0002$, respectively). In group 2 , dose level $\mathrm{V}$ patients had a higher probability of grade $\geq 2$ late GI or GU toxicity compared to dose level II, III, and IV ( $\mathrm{HR}=2.61, \mathrm{p}=0.0002 ; \mathrm{HR}=2.22$, $\mathrm{p}=0.0051 ; \mathrm{HR}=1.60, \mathrm{p}=0.0276$, respectively).

Conclusions-Tolerance to high dose 3DCRT remains excellent. There is significantly more grade $\geq 2$ toxicity with $78 \mathrm{~Gy}$ at $2 \mathrm{~Gy} /$ fraction compared to $68.4 \mathrm{~Gy}$ to $79.2 \mathrm{~Gy}$ at $1.8 \mathrm{~Gy} /$ fraction and 74 Gy at $2 \mathrm{~Gy} /$ fraction.

\section{Introduction}

A radiation dose response for prostate cancer has long been established. Prior to the availability of modern three-dimensional treatment planning systems, attempts at dose escalation above 70 Gy were met with a high rate of rectal and bladder toxicity. The objective of RTOG 9406 was to determine the maximally tolerated dose of 3D conformal radiation therapy (3D CRT) that could be safely administered to men with localized prostate cancer. The primary endpoint of RTOG 9406 is the development of grade 3 or worse late gastrointestinal (GI) or genitourinary (GU) toxicity. Three dose levels were initially planned, 68.4 Gy, 73.8 Gy, and 79.2 Gy. Because dose limiting toxicity was not identified in the first three dose levels, the study remained open to accrue patients to two additional dose levels, $74 \mathrm{~Gy}$ and $78 \mathrm{~Gy}$. The dose per fraction was increased to $2 \mathrm{~Gy} /$ day to minimize the elapsed treatment time associated with the dose escalation. The preliminary results of the acute and late toxicity in all dose levels have been previously reported in a series of publications. ${ }^{1-4}$ In this paper we report long term late toxicity of all men treated from dose levels I to V.

\section{Methods and Materials}

\section{Study design}

Details regarding the clinical trial, radiation dose prescription and quality assurance have been described. ${ }^{1}$ Each participating institution obtained independent review by its Institutional Review Board (IRB) before registering patients. RTOG 9406 was a Phase I/II dose escalation study for men treated with radiation therapy for Stages T1 through T3 non-metastatic carcinoma of the prostate. Each participant provided his informed written consent prior to beginning protocol therapy. The study's primary objectives were to establish the maximum tolerated dose of radiation that can be delivered to the prostate gland and the immediate surrounding tissues in men with prostate cancer using 3D CRT and to quantify the normal tissue complication probabilities (NTCP) for rectum and bladder using 3D CRT. All participating institutions were required to accrue patients to the first dose level of $68.4 \mathrm{~Gy}$ minimum dose to the planning target volume in $1.8 \mathrm{~Gy} /$ day fractions. Once institution compliance to the protocol was established by the 3D QA Center (now Image-guided Therapy quality assurance Center, ITC), registrations to higher dose levels were allowed.

\section{Patient eligibility}

Patients previously untreated with biopsy-proven adenocarcinoma of the prostate, 1992 American Joint Committee on Cancer clinical stages T1 through T3 were eligible, except for patients with T1b-c or T2a-b with Gleason sums $\leq 5$ and PSA $\leq 4 .{ }^{5}$ The upper limit of prostate specific antigen (PSA) for eligibility on this study was $70 \mathrm{ng} / \mathrm{ml}$ and must have been obtained more than 10 days following a prostate biopsy and within 3 months prior to study entry or initiation of hormone therapy. Neoadjuvant androgen blockade beginning 2-6 months prior to registration was allowed as long as a prehormonal PSA was available. Because of slow accrual of patients with stage T3 cancer, the study was closed to these patients after dose level II. 


\section{Treatment planning}

Standardized nomenclature as published by the International Commission on Radiation Units and Measurements (ICRU 50) ${ }^{6}$ was used. Patients were stratified into three treatment groups according to their risk of seminal vesicle invasion. Group 1 patients had clinical stage T1,2 disease with minimal risk of seminal vesicle invasion. Group 2 patients had a risk of seminal vesicle invasion exceeding $15 \%,{ }^{7,8}$ Group 3 patients had clinical stage T3 disease.

\section{Target volume and critical normal structure definition}

The gross tumor volume (GTV) included the entire prostate gland. Elective seminal vesicle irradiation was included as a clinical target volume (CTV1) in patients with group 2 disease. ${ }^{7}$ Group 2 patients then had a second boost volume that encompassed the prostate only (CTV2). Group 3 patients had the prostate and entire seminal vesicles included in the CTV for the entire study dose. The planning target volume (PTV) consisted of the respective CTVs with a 0.5 to $1.0 \mathrm{~cm}$ margin to account for treatment uncertainties from set up or internal organ motion. The ICRU $^{6}$ reference point doses were to be located in the central part of the PTV on or near the central axis of the beam intersections. Normal tissue volumes contoured included the bladder, rectum, bilateral femora, and skin. These organs were contoured as solid structures. These definitions minimized variations in the data submitted for quality assurance review. The tissue within the skin and excluding all other critical normal structures and target volumes was designated as unspecified tissue.

\section{D Conformal Radiation Therapy}

Treatment was administered to the PTVs using 3D conformal fields shaped to exclude as much of the bladder and rectum as possible. Elective pelvic nodal irradiation was not allowed. Group 1 patients had no elective seminal vesicle irradiation. Group 2 patients received treatment initially to PTV1 that encompassed the prostate and seminal vesicles. These patients had a treatment volume reduction after $54 \mathrm{~Gy}$ on the $2 \mathrm{~Gy}$ arms or $55.8 \mathrm{~Gy}$ on the $1.8 \mathrm{~Gy}$ arms that excluded the seminal vesicles. After that dose, the PTV2 received the assigned minimum study dose. Group 3 patients had the prostate and entire seminal vesicles included in the target. DVHs were generated for all critical normal structures and the unspecified tissues. Portions of the bladder and rectum by necessity received the full dose to the PTV because the PTV overlapped with these organs. Careful 3D planning was encouraged to ensure that the volume of the bladder and rectum receiving the full dose was kept to a minimum.

At the start of the trial, radiation doses were prescribed as a minimum to the PTV. This convention would assure complete coverage of the clinical target volume by the prescribed study dose over the entire course of radiation therapy. This PTV minimum dose prescription resulted in the isocenter or ICRU reference point being approximately $4 \%$ higher than the minimum PTV dose. As the study proceeded to dose level III (79.2 Gy) concerns were raised about the risks of rectal toxicity that might be encountered without additional measures to reduce rectal dose. ${ }^{9}$ For dose level III (79.2 Gy at 1.8 Gy/day) only, the prescription convention was changed to a minimum dose to the GTV/CTV while maintaining the minimum PTV dose to at least $73.8 \mathrm{~Gy}$. In practice, a minimum CTV dose prescription kept the isocenter dose 2-3\% higher than 79.2 Gy (average ICRU reference dose $81.6 \mathrm{~Gy}$ ) and the minimum dose the PTV received was only 1-2\% lower than 79.2 Gy (average PTV minimum dose 77.2 Gy). After dose level III the study returned to a minimum PTV dose prescription for dose levels IV and V, 74 Gy and 78 Gy, respectively.

\section{Toxicity scoring}

Late post-treatment gastrointestinal, rectal, or genitourinary complications appearing or persisting greater than 120 days after treatment start were graded according to the RTOG late 
radiation morbidity scoring scale. The late toxicity was score after 120 days rather than 90 days as in other RTOG trials due to the prolonged duration of treatment associated with the dose escalation.

\section{Statistical considerations}

Toxicities are defined as the worst toxicity for each patient occurring from the start of radiation treatment. Acute and late toxicities occurred less than or equal to 120 days and greater than 120 days from the start of radiation treatment, respectively. Cox proportional hazards regression ${ }^{10}$ is used to test whether the hazard ratio is the same between the disease groups within each dose level or between the dose levels within each disease group using the Chisquare test. Also, Cox proportional hazards regression is used to adjust for age $(<70 \mathrm{vs.} \geq 70)$ induction hormone administration (yes vs. no), and dose level (I - V) for each disease group as well as PTVHD volume (continuous) or 3D margin between GTV and PTVHD (continuous) respectively. All two-sided testing is done at a significant level of 0.05 except pairwise comparisons. For pairwise comparisons, Bonferroni methods ${ }^{11}$ are used to keep the overall significance level of 0.05 .

\section{Results}

Between August 23, 1994 and October 30, 2000, 1084 cases were registered on this study. All follow-up information on patients submitted and data entered at RTOG headquarters through October 2007 is included in this analysis. Pretreatment patient characteristics and median follow-up at time of this analysis are listed in Table 1. The median follow-up for patients treated in level I exceeds 12 years and for level V it exceeds 6 years. The mean ICRU reference doses delivered to patients in each patient grouping and prescription dose level for the current study are listed in Table 1. Because minimum dose prescriptions to the PTV (CTV on level III) were used, the ICRU reference doses are approximately $4 \%$ greater than the minimum PTV dose. These are actual doses delivered based upon final dosimetry review by the RTOG 3D QA Center.

The protocol allowed treating physicians to use a range 5 to $10 \mathrm{~mm}$ for the CTV to PTV margins. Institutions were encouraged to systematically evaluate their setup error and internal organ motion for their patient population, localization and immobilization methods. For dose level I, II, III, IV, and V the average PTV margins were $6.96 \mathrm{~mm}, 7.00 \mathrm{~mm}, 6.92 \mathrm{~mm}, 7.49 \mathrm{~mm}$ and $7.76 \mathrm{~mm}$, respectively. The margins used in the latter dose levels were statistically significantly larger than the margin used in the earlier arms of the study ( $<<0.05)$. For this reason we examined both PTV margin and the volume of the high dose PTV (PTV-HD) in the multivariate analyses examining toxicity by treatment arm.

The primary endpoint of this study is the incidence of RTOG late grade 3 or worse GI or GU toxicity. In this report the incidence of GI and GU toxicities are reported collectively and separately to allow comparison with other published series. The incidences of late grade 3 or worse GI or GU toxicity in group 1 were 3\%, 4\%, 6\%, 7\% and 9\% and those for group 2 were $6 \%, 2 \%, 6 \%, 9 \%$, and $12 \%$ at dose levels I, II, III, IV and V, respectively. Group 3 patients who were treated with dose level II showed $6 \%$ of late grade 3 or worse GI/GU toxicity. The incidences of grade 3 or worse GI toxicity are $1 \%, 0 \%, 1 \%, 3 \%$ and $4 \%$ for group 1 and 3\%, $0 \%, 3 \%, 2 \%$ and $7 \%$ for group 2 at dose levels I through V. The incidences of grade 3 or worse GU toxicity are $1 \%, 4 \%, 5 \%, 3 \%$ and $5 \%$ for group 1 and $3 \%, 2 \%, 3 \%, 6 \%$ and $6 \%$ for group 2.

The rates of late grade 3 toxicities are not significantly large enough to be modeled. The incidences of RTOG late grade 2 or worse GI, GU, and GI or GU toxicity were analyzed instead. For levels I to III (1.8Gy fraction size) the incidence of grade 2 or worse GI or GU toxicity 
ranges from 21 to $31 \%$ in groups 1 and 2 and $44 \%$ for group 3 treated to dose level II. For dose levels IV and V (2.0 Gy fraction size), the incidence of grade 2 or worse GI or GU toxicity ranged from $32 \%$ to $44 \%$ for groups 1 and 2 . The incidences of grade 2 or worse GI toxicity are $9 \%, 7 \%, 11 \%, 10 \%$ and $25 \%$ for group 1 and $13 \%, 9 \%, 14 \%, 16 \%$ and $26 \%$ for group 2 at dose levels I through $\mathrm{V}$. The incidences of grade 2 or worse GU toxicity are $24 \%, 22 \%, 18 \%$, $29 \%$ and $23 \%$ for group 1 and 19\%, 16\%, 21\%, 21\% and 28\% for group 2. Figures 1 and 2 show the cumulative incidences of time to late grade 2 or worse GI, GI, and GI or GU toxicity for disease groups 1 and 2, respectively. There is a significantly higher incidence of grade 2 or worse GI toxicity for patients receiving $78 \mathrm{~Gy}$ ( $\mathrm{p}=0.0001$ for group 1 and $\mathrm{p}=0.0063$ for group 2 ). There is no similar increase in grade 2 or worse GU toxicity ( $\mathrm{p}=0.2067$ for group 1 and $\mathrm{p}=0.2021$ for group 2 ). As for grade 2 or worse GI or GU toxicity, there is a significantly higher incidence of toxicity for the 78 Gy level ( $\mathrm{p}=0.0005$ for group 1 and $\mathrm{p}=0.0016$ for group 2 ).

Patients treated with dose level V have a higher probability of grade 2 or worse GI toxicity but no significant increase in grade 2 or worse GU toxicity compared to levels I, II, III and IV in group 1 and levels II, III, and IV in group 2 patients. In the disease group 1, patients who are treated with dose level V have higher probability of grade 2 or worse late GU or GI toxicity compared to dose level I, II, and III (Table 2). Also in the disease group 2, patients who are treated with dose level V have higher probability of grade 2 or worse late GU or GI toxicity compared to dose level II, III, and IV. These differences are primarily related to GI toxicity.

We analyzed these results in a multivariate analysis which adjusted for age, induction hormone, PTVHD volume (Table 3) or 3D margin between GTV and PTVHD(Table 4). The results remained the same in groups 1 and 2 . While in some instances the magnitude of the margins or the size of the PTV-HD volume may have contributed to an increase in GI or GU toxicity, the effect of the 78Gy in $2.0 \mathrm{~Gy}$ day fractions remained a significant factor for toxicity.

In group 3, we did not compare the two dose levels (I vs. II) since there are only 4 patients in dose level I. In a univariate Cox proportional hazard model, patients in group 3 did experience a higher rate of grade 2 or worse GI toxicity than patients in groups 1 or 2 (HR 3.87, p=0.0017). There were no significant covariates associated with late grade 2 or worse GI or GU toxicity for group 3 patients.

\section{Discussion}

This is an update of toxicity results following 3D conformal radiation therapy on RTOG 9406, a phase I/II dose escalation trial for early stage prostate cancer. The primary objective of this trial was to determine the maximally tolerated dose of radiation therapy that could be delivered to the prostate gland and immediate surrounding tissues using modern conformal techniques. The primary endpoint was the development of grade 3 or greater GI or GU toxicity. Our prior publications compared patients treated on this trial to men treated with non-conformal therapy from clinical trials initiated in the late 1970s. Those data showed that there was a significant reduction in grade 3 or greater toxicity, despite radiation doses that were more than $10 \mathrm{~Gy}$ higher. ${ }^{1-4}$ Because of the low rates of grade 3 toxicity, we also examined rates grade 2 or greater toxicity. While not considered serious, these toxicities are of sufficient severity that they may impact on a patient's quality of life. The ongoing phase III RTOG dose trial is collecting patient reported outcomes to supplement the standard reporting of the RTOG and NCI common toxicity criteria.

In this analysis we examine all five dose levels and compare results amongst each treatment arm. It should be noted that with the exception of level 3, all patients were prescribed treatment as a minimum dose to the PTV. Level 3 patients had treatment prescribed as a minimum to the CTV with the intent to keep the PTV and rectum overlapping it to 73.8Gy or less. In practice, 
such a sharp dose gradient is difficult to achieve with 3D CRT and the average minimum PTV dose (and anterior rectal wall dose) on this arm was 77.2Gy.

Patients were initially stratified into three arms by their risk of seminal vesicle invasion. Group 3 patients represent those with clinical evidence of extraprostatic extension (clinical stage T3) and it was intended to treat the prostate and entire seminal vesicles to the full study dose.

Because of the declining incidence of stage $\mathrm{T} 3$ cancers it was necessary to close this study to this group of patients because accrual rates were too slow. Therefore, only level II had sufficient group 3 patients to analyze. Despite a modest dose escalation to $73.8 \mathrm{~Gy}$, patients with group 3 disease had a significantly higher rate of grade 2 or greater late toxicity compared to other patients treated to this same level. This is likely due to the larger volume of rectum irradiated when the seminal vesicles are included as part of the high dose target volume. Caution should be exercised when treating patients with stage T3 to doses of 73.8Gy or greater with 3D CRT because of the higher rate of toxicity seen in this trial with modest dose escalation. The multivariate analysis also demonstrates that an increasing size of the margins or high dose PTV may contribute to toxicity.

The rates of grade 2 or greater toxicity seen in this trial are comparable to those reported in recent prospective clinical trials. In the MD Anderson randomized dose trial the 10 year incidence of grade 2 or greater GI toxicity was $13 \%$ and $26 \%$ for $70 \mathrm{~Gy}$ for $78 \mathrm{~Gy}$ arms, respectively. The 10 year incidence of grade 2 or greater GU toxicity was $8 \%$ and $13 \%$ for the 70Gy and 78Gy arms, respectively. ${ }^{12}$ In a Dutch randomized 3DCRT dose trial, the 5 year late $\geq$ grade 2 GI toxicity rate was $27 \%$ and $32 \%$ in the $68 \mathrm{~Gy}$ and $78 \mathrm{~Gy}$ arms, respectively. The 5 year late $\geq$ grade 2 GU toxicity rate was $41 \%$ and $39 \%$ in the $68 \mathrm{~Gy}$ and $78 \mathrm{~Gy}$ arms, respectively. ${ }^{13}$ Similarly, the MRC randomized trial of 64 Gy vs 74 Gy reported 5 year late $\geq$ grade 2 GI toxicity rates of $24 \%$ and $33 \%$ in the standard and escalated dose arms, respectively. The 5 year late $\geq$ grade $2 \mathrm{GU}$ toxicity rates were $8 \%$ and $11 \%$, respectively. ${ }^{14}$ In the Proton Radiation Oncology Group trial, Zietman reported late $\geq$ grade 2 GI morbidity of $8 \%$ and $17 \%$ for the $70.2 \mathrm{~Gy}$ and $79.2 \mathrm{~Gy}$ arms, respectively and $\geq$ grade $2 \mathrm{GU}$ morbidity of $18 \%$ and $20 \%$, respectively. 15

Patients treated to the last dose level, 78Gy in 2Gy/day fractions had the highest level of grade 2 or greater toxicity. In both univariate and multivariate analyses, patients treated on this level had a significantly higher rate of GI and GU late effects compared to those treated at lower levels. It is difficult to determine if this is solely due to fraction size, especially considering that the patients treated to level III, 79.2Gy in $1.8 \mathrm{~Gy}$ fractions, had a slightly different prescription method. Furthermore, these patients had a PTV margin that was nearly $1 \mathrm{~mm}$ larger than the patients treated to the lower doses at $1.8 \mathrm{~Gy}$. However, despite the differences in prescription method, the average minimum PTV dose in the level III cohort was $77.2 \mathrm{~Gy}$, very close to the minimum dose for the level 5 cohort. Furthermore, while not a statistically difference, even the $74 \mathrm{~Gy}$ in 2Gy/day fractions arm had a hazard ratio for grade 2 or greater toxicity that was greater than 1 (table $5 \mathrm{c}, \mathrm{HR}=1.65$, $\mathrm{p}$-value $=0.0513$ ), suggesting an effect related to the $2 \mathrm{~Gy}$ fraction size. It is important to emphasize that the $2 \mathrm{~Gy}$ arms have the shortest follow-up and it is possible that additional late effects could still occur for these two cohorts.

Patients in this trial were treated exclusively with 3D conformal and not intensity modulated radiation therapy (IMRT). Data from the Memorial Sloan Kettering dose escalation trial suggests that IMRT may allow safe dose escalation to doses higher than can be achieved with 3DCRT and higher than those used in this trial. ${ }^{16}$ IMRT significantly reduces the volumes of rectum and bladder that receive moderate to high radiation doses. In their experience the use of IMRT significantly reduced the rate of $\geq$ Grade 2 late GI toxicity from $13 \%$ to $5 \%$. It should be noted that treatment planning parameters from that series and the RTOG experience differ, particularly with respect to PTV volume and its overlap with the rectum. 
The dose-volume and clinical data from this trial is being used to generate predictive toxicity models. Quantitative dose volume histogram information as well as the spatial distribution of doses to the rectum and bladder are being analyzed to provide clinicians and researchers with tools to minimize toxicity to patients treated for early stage prostate cancer. These analyses will be the subject of future manuscripts.

Hypofractionation for localized prostate cancer has become a popular treatment schedule for clinical investigation. Based upon data from permanent low dose rate as well as temporary high dose rate brachytherapy, many have argued that the alpha/beta ratio for prostate cancer is low, in the range of 1.5 to $3 .{ }^{17-19}$ Kupelian et al have published results of treatment with a short course of hypofractionated intensity modulated radiation therapy in 100 men with a median of 45 months of followup. ${ }^{20}$ In that series men with T1-T3 prostate cancer were treated with $70 \mathrm{~Gy}$ in $2.5 \mathrm{~Gy} /$ day fractions over $51 / 2$ weeks. The late toxicity was no worse than their historical controls. The 5 year actuarial rate of grade 2 and 3 rectal toxicity was $6 \%$ and $2 \%$, respectively. The 5 year actuarial rate of grade 2 urinary toxicity was $7 \%$. It is worth noting that all those patients were treated with IMRT and daily localization with either an ultrasound system using PTV margins of only $4 \mathrm{~mm}$ posteriorly. Patients in the RTOG 9406 trial were treated with 3DCRT and not IMRT. PTV margins ranged from 5-10mm around the CTV. Despite these technical differences, the higher rates of late morbidity seen with just a $10 \%$ increase in the daily fraction size in the $2 \mathrm{~Gy}$ arms emphasizes that the rectum may be sensitive to small changes in dose per fraction. While the RTOG is investigating hypofractionation in an ongoing clinical trial, it should be emphasized that large fraction sizes are currently not a standard of care. Radical changes in the dose per fraction that are being proposed by proponents of stereotactic radiation therapy should be conducted in the context of a clinical trial. ${ }^{21}$

\section{Conclusion}

Dose escalation to $79.2 \mathrm{~Gy}$ in 44 fractions of $1.8 \mathrm{~Gy}$ daily is well tolerated in men with early stage prostate cancer and can safely be delivered in the context of a multi-institutional clinical trial. A dose of $78 \mathrm{~Gy}$ in 39 fractions of $2 \mathrm{~Gy}$ per fraction is associated with a significantly increased rate of moderately severe late toxicity compared to similar doses delivered at $1.8 \mathrm{~Gy}$ per fraction. An RTOG prospective clinical randomized trial to determine if dose escalation will lead to an improvement in overall survival in men with intermediate risk prostate cancer is underway.

\section{Acknowledgments}

This publication was supported by grant number (RTOG U10 CA21661, CCOP U10 CA37422, Stat U10 CA32115, ITC U24 CA081647) from the National Cancer Institute. Its contents are solely the responsibility of the authors and do not necessarily represent the official views of the National Cancer Institute.

\section{References}

1. Michalski J, Purdy JA, Winter K, et al. Preliminary report of toxicity following 3D radiation therapy for prostate cancer on 3DOG/RTOG 9406. Int J Radiat Oncol Biol Phys 2000;46:391-402. [PubMed: 10661346]

2. Michalski JM, Winter K, Purdy JA, et al. Toxicity after three-dimensional radiotherapy for prostate cancer on RTOG 9406 dose Level V. Int J Radiat Oncol Biol Phys 2005;62:706-713. [PubMed: 15936549]

3. Michalski JM, Winter K, Purdy JA, et al. Toxicity after three-dimensional radiotherapy for prostate cancer with RTOG 9406 dose level IV. Int J Radiat Oncol Biol Phys 2004;58:735-742. [PubMed: 14967428]

4. Ryu JK, Winter K, Michalski JM. Preliminary report of toxicity following 3D conformal radiation therapy (3DCRT) for prostate cancer on 3DOG/RTOG 9406, level III (79.2 Gy). Int J Tadiat oncol Biol Phys 2001;51:136-137. 
5. Ryu JK, Winter K, Michalski JM, et al. Interim report of toxicity from 3D conformal radiation therapy (3D-CRT) for prostate cancer on 3DOG/RTOG 9406, level III (79.2 Gy). Int J Radiat Oncol Biol Phys 2002;54:1036-1046. [PubMed: 12419429]

6. ICRU 50 Report 50. Prescribing, recording, and reporting photon beam therapy. Bethesda, MD: International Commission on Radiation Units and Measurement; 1993.

7. Diaz A, Roach M, Marquez C, et al. Indications for and the significance of seminal vesicle irradiation during 3D conformal radiotherapy for localized prostate cancer. Int J Radiat Oncol Biol Phys 1994;30:323-329. [PubMed: 7523343]

8. Roach M 3rd. Re: The use of prostate specific antigen, clinical stage and Gleason score to predict pathological stage in men with localized prostate cancer. J Urol 1993;150:1923-1924. [PubMed: 7693984]

9. Lee WR, Hanks GE, Hanlon AL, et al. Lateral rectal shielding reduces late rectal morbidity following high dose three-dimensional conformal radiation therapy for clinically localized prostate cancer: further evidence for a significant dose effect. Int J Radiat Oncol Biol Phys 1996;35:251-257. [PubMed: 8635930]

10. Cox DR. Regression models and life tables. J Royal Stat Soc, Series B 1972;34:187-229.

11. Bonferroni CE. Teoria statistica delle classi e calcolo delle probabailit. Pubblicazioni del R Istituto Superiore di Scienze Economiche di Firenze 1936;8:3-62.

12. Kuban, DA.; Tucker, SL.; Dong, L., et al. Int J Radiat Oncol Biol Phys. Vol. 70. 2008. Long-term results of the M. D. Anderson randomized dose-escalation trial for prostate cancer; p. 67-74.Epub 2007 Aug 2031

13. Peeters ST, Heemsbergen WD, Koper PC, et al. Dose-response in radiotherapy for localized prostate cancer: results of the Dutch multicenter randomized phase III trial comparing 68 Gy of radiotherapy with 78 Gy. J Clin Oncol 2006;24:1990-1996. [PubMed: 16648499]

14. Dearnaley DP, Sydes MR, Graham JD, et al. Escalated-dose versus standard-dose conformal radiotherapy in prostate cancer: first results from the MRC RT01 randomised controlled trial. Lancet Oncol 2007;8:475-487. [PubMed: 17482880]

15. Zietman AL, DeSilvio ML, Slater JD, et al. Comparison of conventional-dose vs high-dose conformal radiation therapy in clinically localized adenocarcinoma of the prostate: a randomized controlled trial. JAMA 2005;294:1233-1239. [PubMed: 16160131]

16. Zelefsky MJ, Levin EJ, Hunt M, et al. Incidence of late rectal and urinary toxicities after threedimensional conformal radiotherapy and intensity-modulated radiotherapy for localized prostate cancer. Int J Radiat Oncol Biol Phys 2008;70:1124-1129. [PubMed: 18313526]

17. Brenner DJ, Hall EJ. Fractionation and protraction for radiotherapy of prostate carcinoma. Int J Radiat Oncol Biol Phys 1999;43:1095-1101. [PubMed: 10192361]

18. Fowler J, Chappell R, Ritter M. Is alpha/beta for prostate tumors really low? Int J Radiat Oncol Biol Phys 2001;50:1021-1031. [PubMed: 11429230]

19. King CR, Fowler JF. A simple analytic derivation suggests that prostate cancer alpha/beta ratio is low. Int J Radiat Oncol Biol Phys 2001;51:213-214. [PubMed: 11516871]

20. Kupelian PA, Willoughby TR, Reddy CA, et al. Hypofractionated intensity-modulated radiotherapy (70 Gy at 2.5 Gy per fraction) for localized prostate cancer: Cleveland Clinic experience. Int J Radiat Oncol Biol Phys 2007;68:1424-1430. Epub 2007 Jun 1424. [PubMed: 17544601]

21. Madsen BL, Hsi RA, Pham HT, et al. Stereotactic hypofractionated accurate radiotherapy of the prostate (SHARP), 33.5 Gy in five fractions for localized disease: first clinical trial results. Int J Radiat Oncol Biol Phys 2007;67:1099-1105. [PubMed: 17336216] 


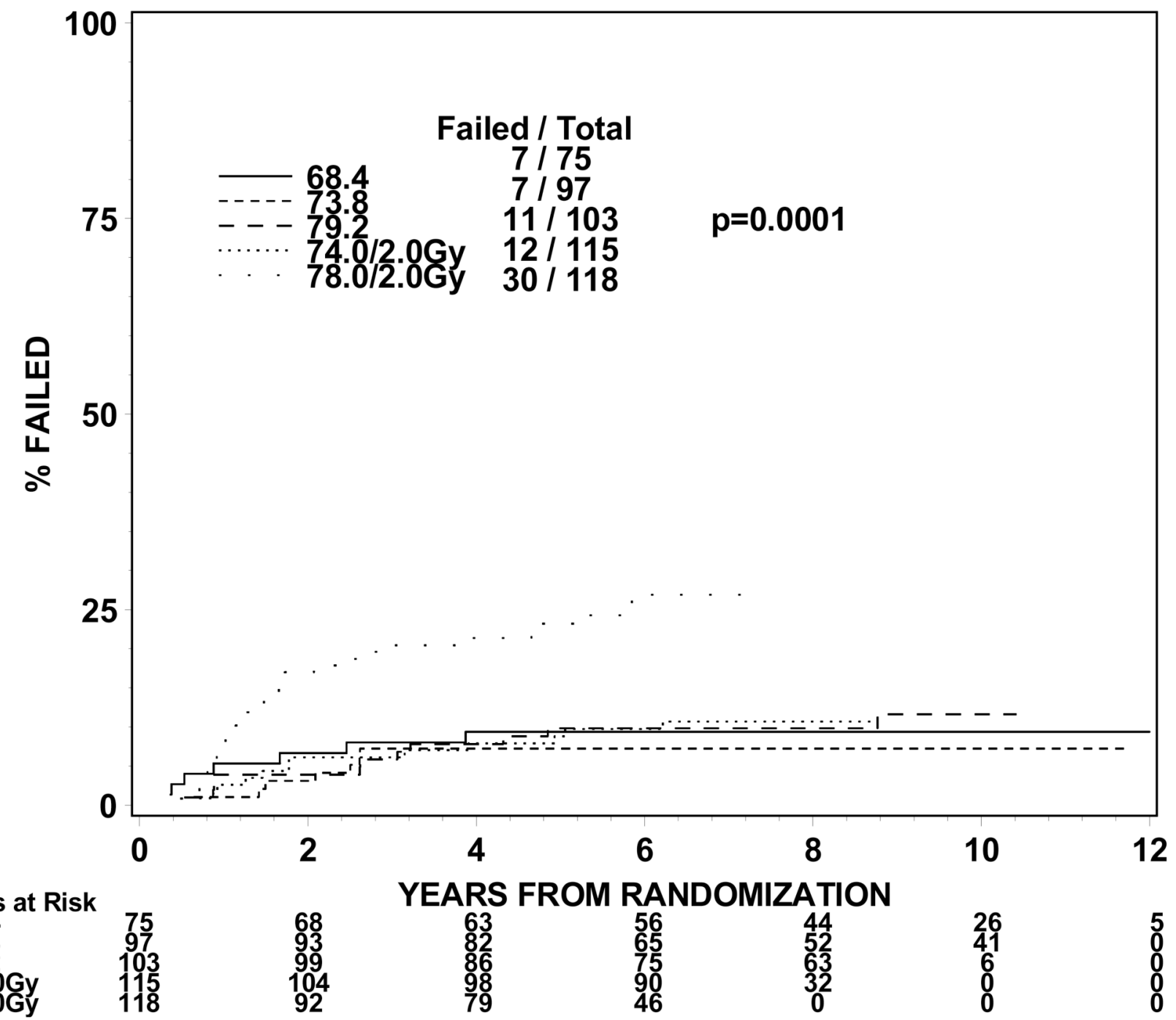
Patients at Risk 79. 74.0/2.0Gy

92

$\begin{array}{ll}\text { ATION } & \\ 44 & 26 \\ 52 & 41 \\ 63 & 6 \\ 32 & 0 \\ 0 & 0\end{array}$

12

5
0
0 


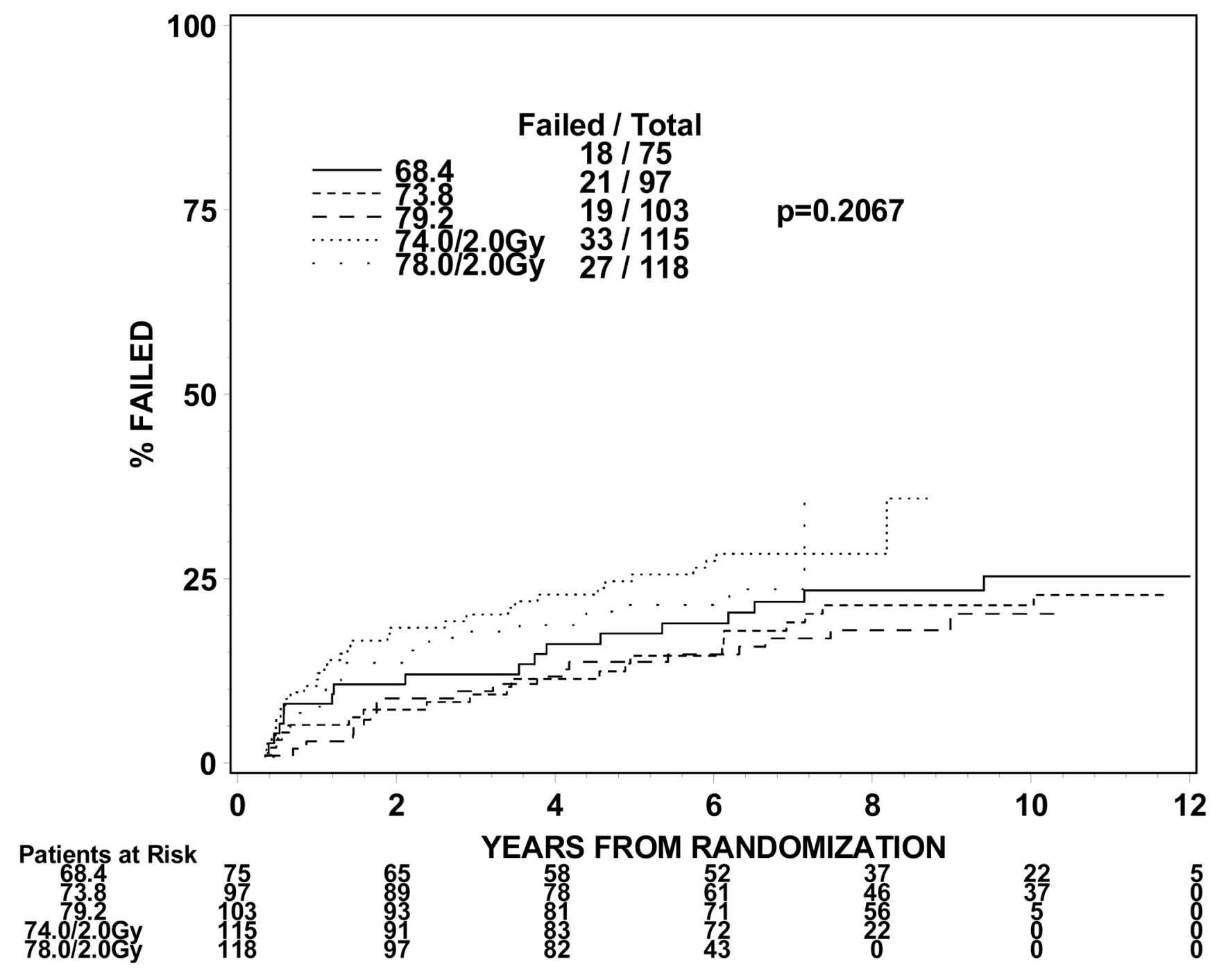

Patients at Risk

74.0.0.20.06\%
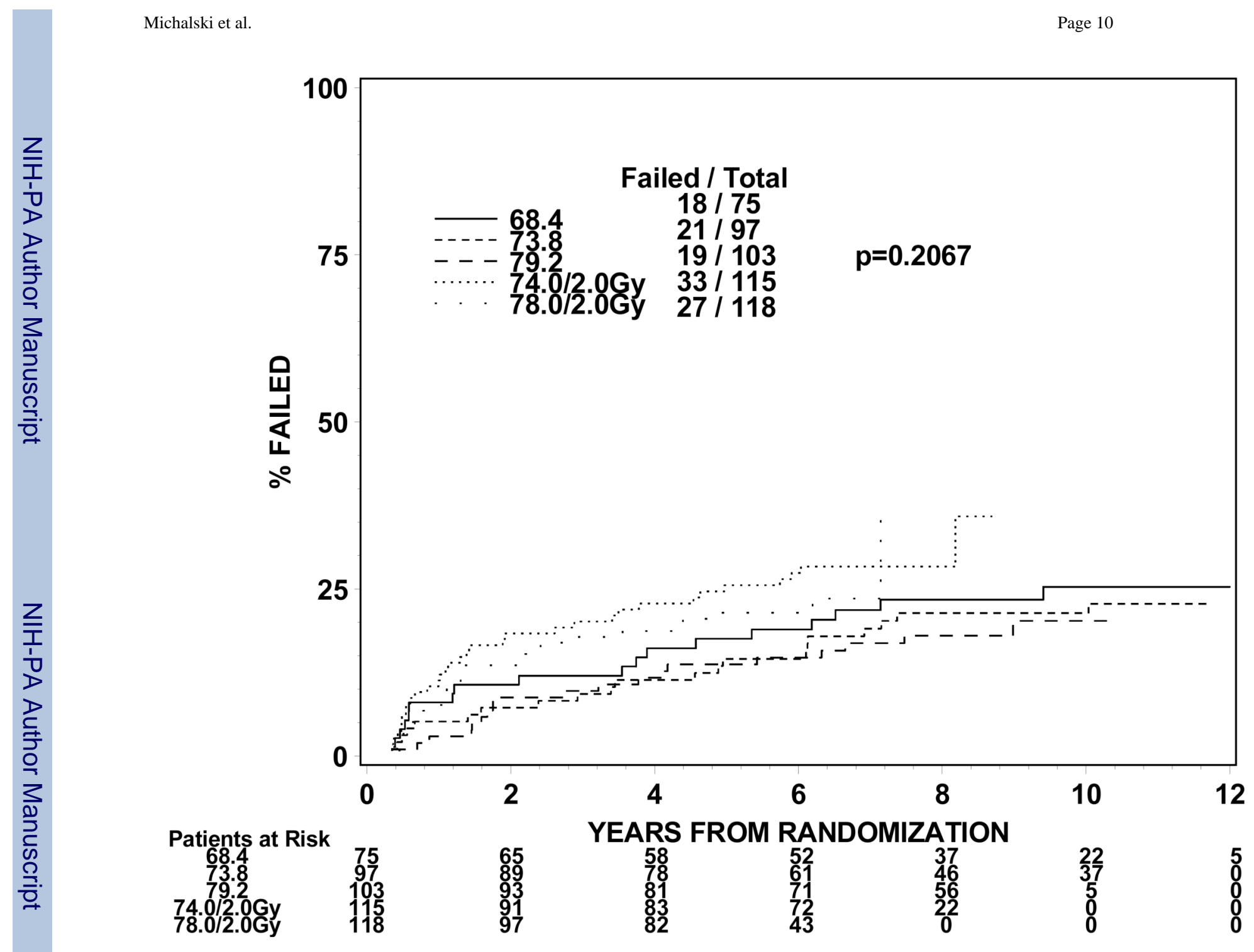

Int J Radiat Oncol Biol Phys. Author manuscript; available in PMC 2011 January 1. 


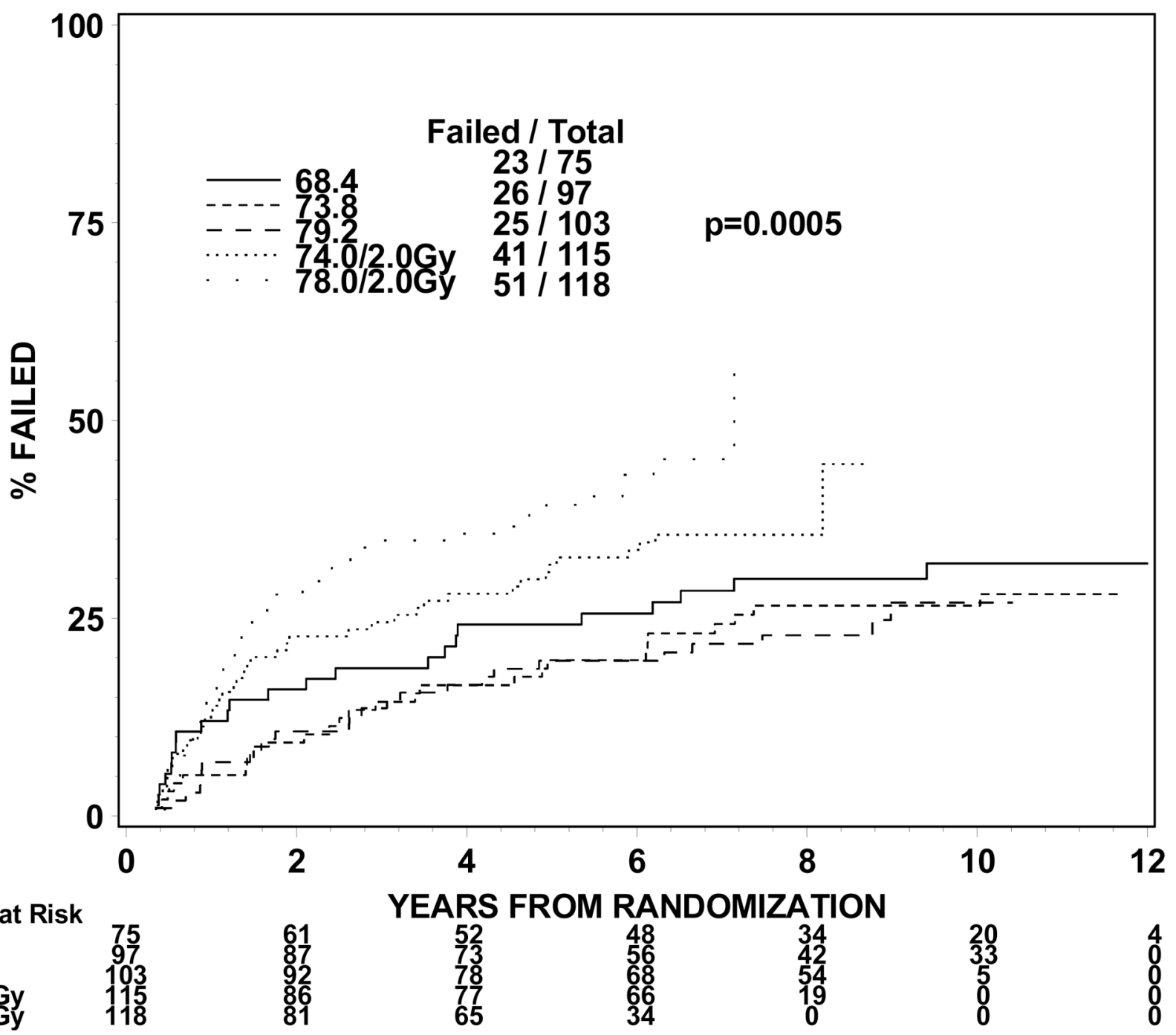

Figure 1.

Figure 1a. Disease group 1, Time to Late GI Grade 2+ (The cumulative incidence method is used to estimate the time to late GI grade 2+ failure rate and the Gray's test is used to test the difference between the levels in this univariate analysis.)

Figure 1b. Disease group 1, Time to Late GU Grade 2+ (The cumulative incidence method is used to estimate the time to late GU grade 2+ failure rate and the Gray's test is used to test the difference between the levels in this univariate analysis.)

Figure 1c. Disease group 1, Time to Late GI/GU Grade 2+ (The cumulative incidence method is used to estimate the time to late GI/GU grade 2+ failure rate and the Gray's test is used to test the difference between the levels in this univariate analysis.) 

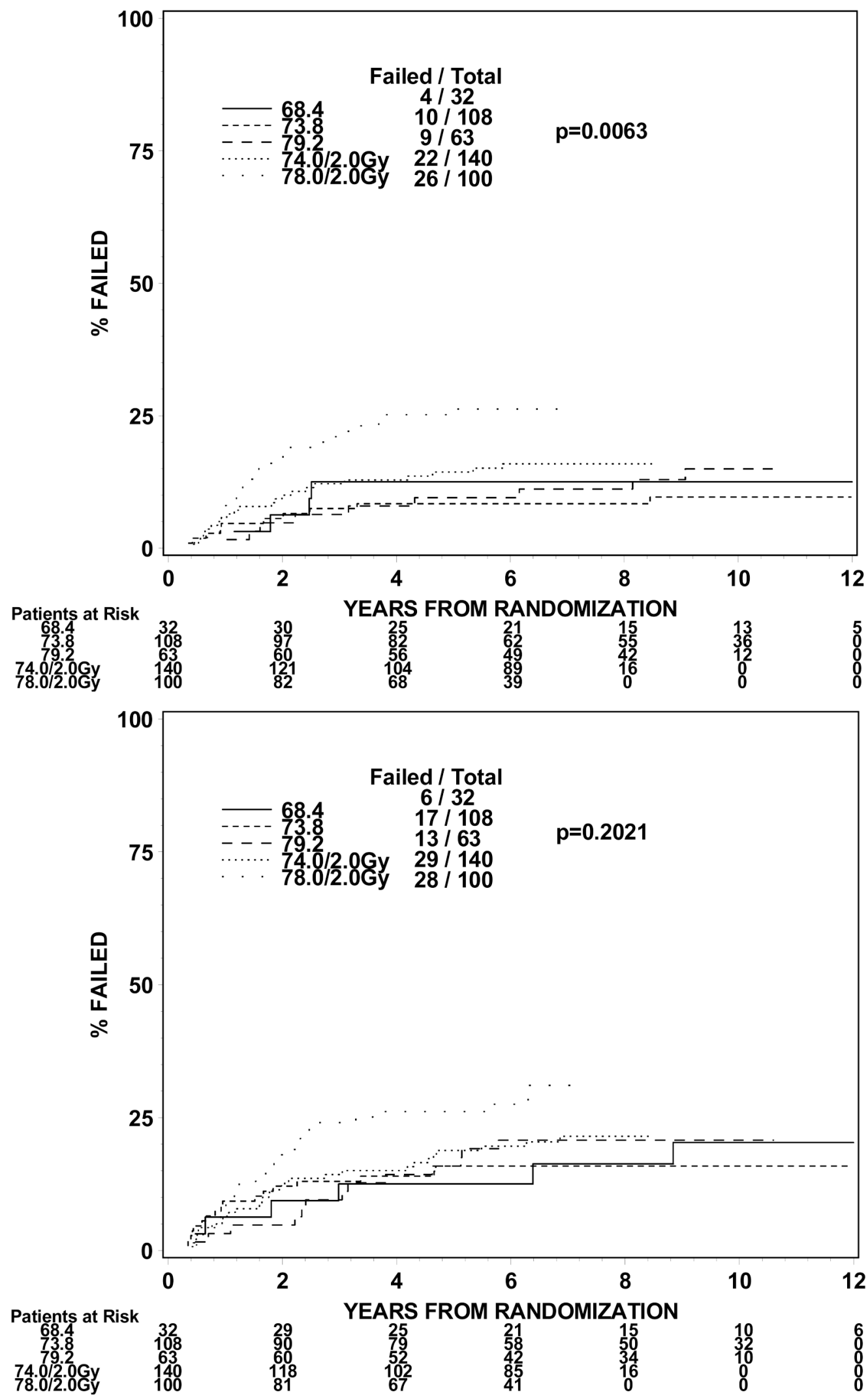

Int J Radiat Oncol Biol Phys. Author manuscript; available in PMC 2011 January 1. 


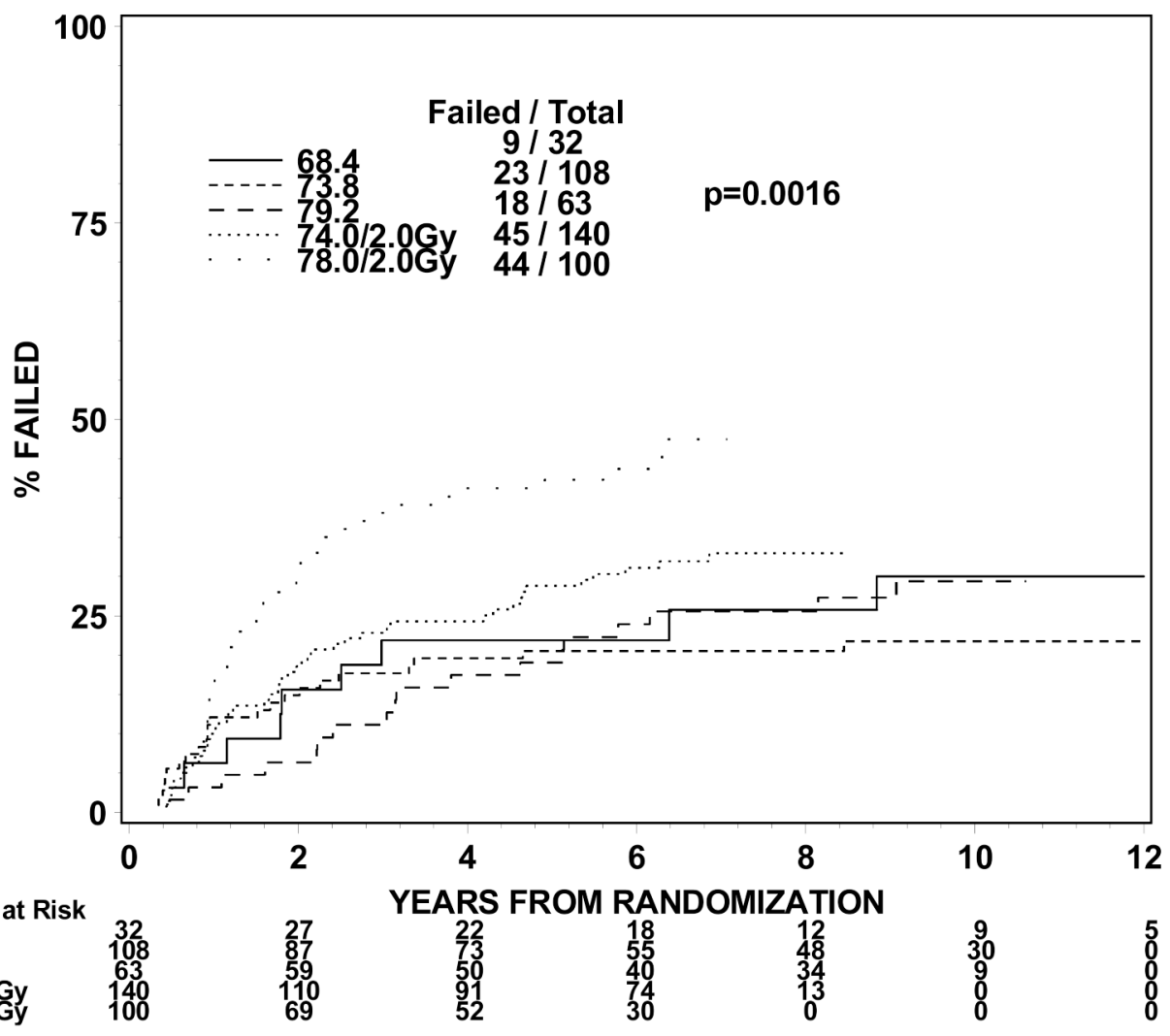

Figure 2.

Figure 2a. Disease group 2, Time to Late GI Grade 2+ (The cumulative incidence method is used to estimate the time to late GI grade 2+ failure rate and the Gray's test is used to test the difference between the levels in this univariate analysis.)

Figure 2b. Disease group 2, Time to Late GU Grade 2+ (The cumulative incidence method is used to estimate the time to late GU grade 2+ failure rate and the Gray's test is used to test the difference between the levels in this univariate analysis.)

Figure 2c. Disease group 2, Time to Late GI/GU Grade 2+ (The cumulative incidence method is used to estimate the time to late GI/GU grade 2+ failure rate and the Gray's test is used to test the difference between the levels in this univariate analysis.) 


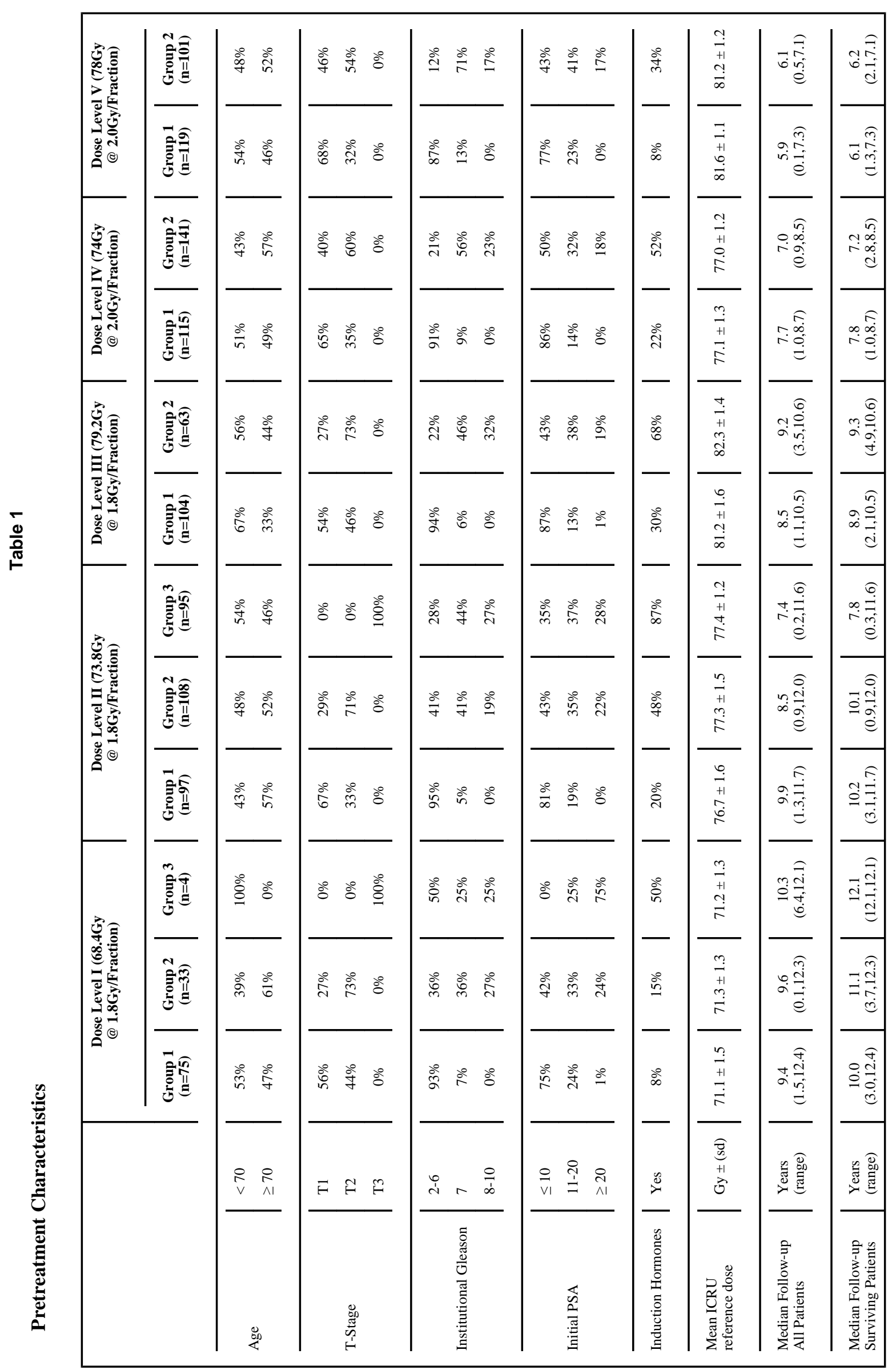

Int J Radiat Oncol Biol Phys. Author manuscript; available in PMC 2011 January 1. 
Table 2

Univariate Cox Proportional Hazard Model-Time to Late GI/GU Grade 2+ Toxicity in Disease Group

\begin{tabular}{|c|c|c|c|c|}
\hline \multirow{2}{*}{$\begin{array}{l}\text { Disease Group } \\
\text { Group } 1\end{array}$} & \multicolumn{2}{|c|}{ Comparison } & \multirow{2}{*}{$\begin{array}{c}\begin{array}{c}\mathbf{H R}^{*} \\
(\mathbf{9 5 \%} \text { C.I. })\end{array} \\
0.84 \\
(0.48,1.47)\end{array}$} & \multirow{2}{*}{$\frac{\text { p-value }^{* *}}{0.5459}$} \\
\hline & Dose Level I & Dose Level II & & \\
\hline & & Dose Level III & $\begin{array}{c}0.77 \\
(0.43,1.35)\end{array}$ & 0.3544 \\
\hline & & Dose Level IV & $\begin{array}{c}1.33 \\
(0.79,2.22)\end{array}$ & 0.2826 \\
\hline & & Dose Level V & $\begin{array}{c}1.93 \\
(1.17,3.18)\end{array}$ & $0.0101^{\dagger}$ \\
\hline & Dose Level II & Dose Level III & $\begin{array}{c}0.91 \\
(0.52,1.58)\end{array}$ & 0.7346 \\
\hline & & Dose Level IV & $\begin{array}{c}1.58 \\
(0.96,2.59)\end{array}$ & 0.0723 \\
\hline & & Dose Level V & $\begin{array}{c}2.29 \\
(1.42,3.71)\end{array}$ & $0.0007^{\dagger \dagger}$ \\
\hline & Dose Level III & Dose Level IV & $\begin{array}{c}1.74 \\
(1.05,2.86)\end{array}$ & 0.0306 \\
\hline & & Dose Level V & $\begin{array}{c}2.52 \\
(1.56,4.10)\end{array}$ & $0.0002^{\dagger \dagger \dagger}$ \\
\hline & Dose Level IV & Dose Level V & $\begin{array}{c}1.46 \\
(0.96,2.20)\end{array}$ & 0.0761 \\
\hline \multirow[t]{9}{*}{ Group 2} & \multirow[t]{4}{*}{ Dose Level I } & Dose Level II & $\begin{array}{c}0.78 \\
(0.36,1.69)\end{array}$ & 0.5323 \\
\hline & & Dose Level III & $\begin{array}{c}0.92 \\
(0.41,2.05)\end{array}$ & 0.8408 \\
\hline & & Dose Level IV & $\begin{array}{c}1.28 \\
(0.62,2.62)\end{array}$ & 0.5051 \\
\hline & & Dose Level V & $\begin{array}{c}2.04 \\
(0.99,4.20)\end{array}$ & 0.0526 \\
\hline & \multirow[t]{3}{*}{ Dose Level II } & Dose Level III & $\begin{array}{c}1.18 \\
(0.64,2.18)\end{array}$ & 0.6033 \\
\hline & & Dose Level IV & $\begin{array}{c}1.63 \\
(0.98,2.72)\end{array}$ & 0.0591 \\
\hline & & Dose Level V & $\begin{array}{c}2.61 \\
(1.56,4.35)\end{array}$ & $0.0002^{\dagger \dagger}$ \\
\hline & \multirow[t]{2}{*}{ Dose Level III } & Dose Level IV & $\begin{array}{c}1.39 \\
(0.80,2.41)\end{array}$ & 0.2474 \\
\hline & & Dose Level V & $\begin{array}{c}2.22 \\
(1.27,3.87)\end{array}$ & $0.0051^{\dagger \dagger \dagger}$ \\
\hline
\end{tabular}




\begin{tabular}{|c|c|c|c|c|}
\hline Disease Group & $\mathbf{R L}$ & rison & $\begin{array}{c}\text { HR }^{*} \\
(95 \% \text { C.I. })\end{array}$ & p-value $e^{* * *}$ \\
\hline & Dose Level IV & Dose Level V & $\begin{array}{c}1.60 \\
(1.05,2.43)\end{array}$ & $\mathbf{0 . 0 2 7 6}^{\dagger+t \dagger}$ \\
\hline
\end{tabular}

*Hazard ratio: A hazard ratio quantifies how much more (less) risk patients at some level have than those at the reference level (RL). A confidence interval that includes 1 indicates that no difference exists between the subgroups.

$* *$

p-value from Chi-square test using the Cox proportional hazards model

${ }^{\dagger}$ It is statistically significant at the significance level of $0.05 / 4=0.012$

${ }^{\dagger \dagger}$ It is statistically significant at the significance level of $0.05 / 3=0.016$

${ }^{\dagger \dagger}$ It is statistically significant at the significance level of $0.05 / 2=0.025$

${ }^{t \dagger \dagger}$ It is statistically significant at the significance level of 0.05 


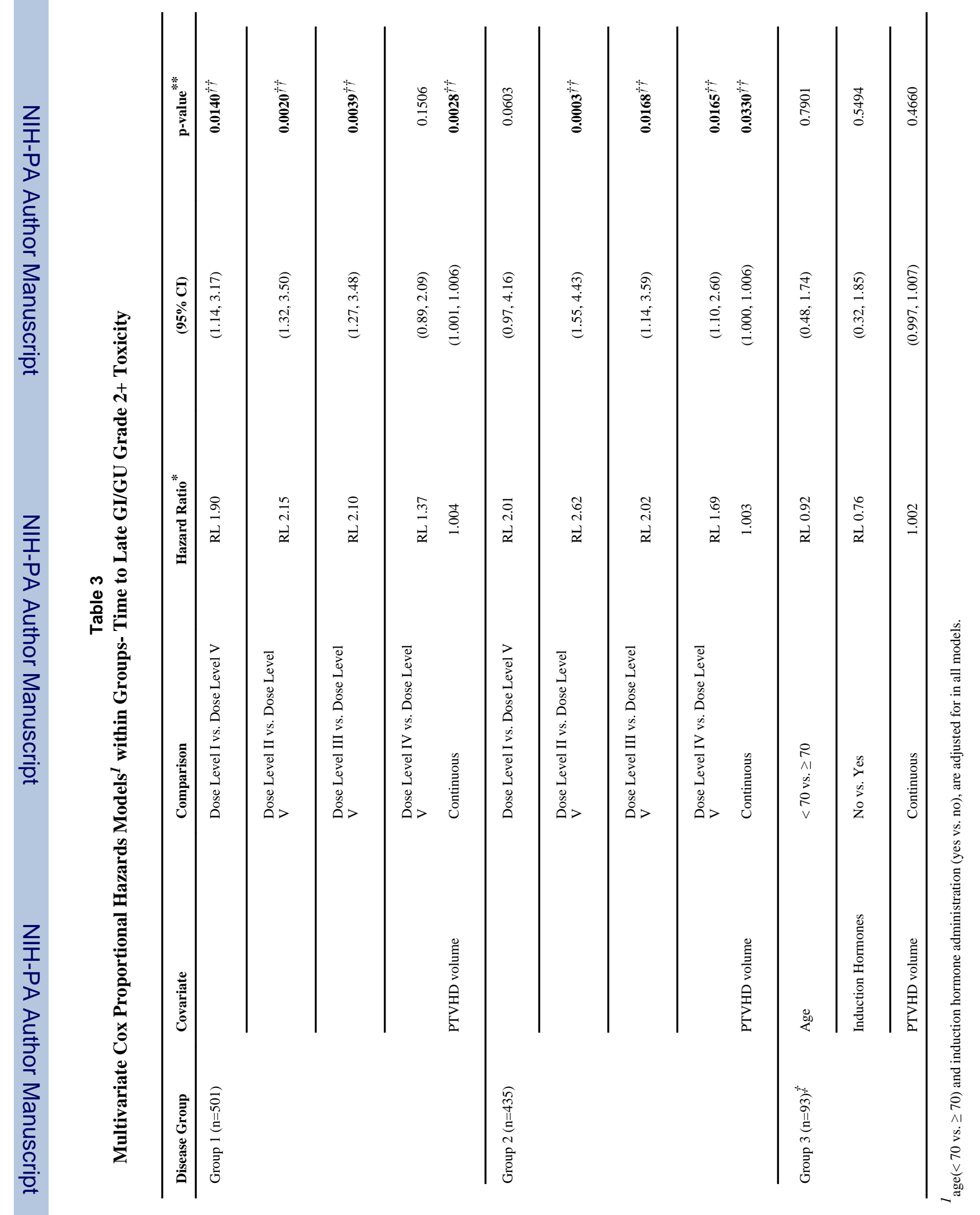




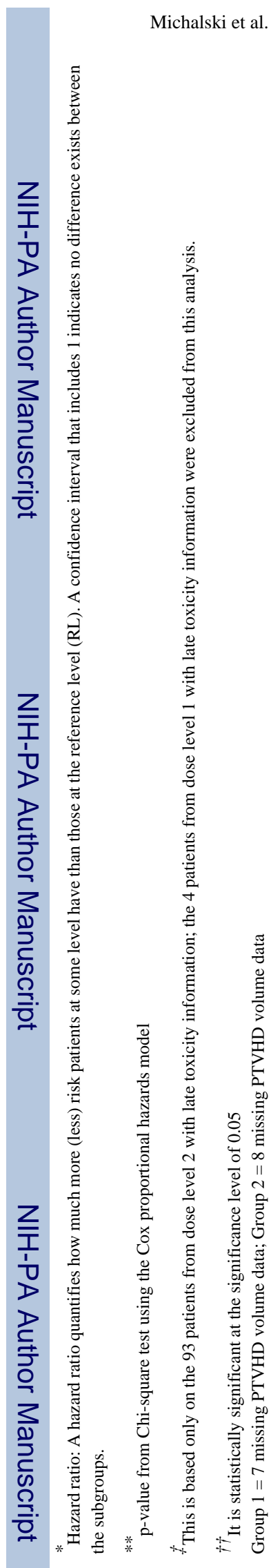

Int J Radiat Oncol Biol Phys. Author manuscript; available in PMC 2011 January 1. 


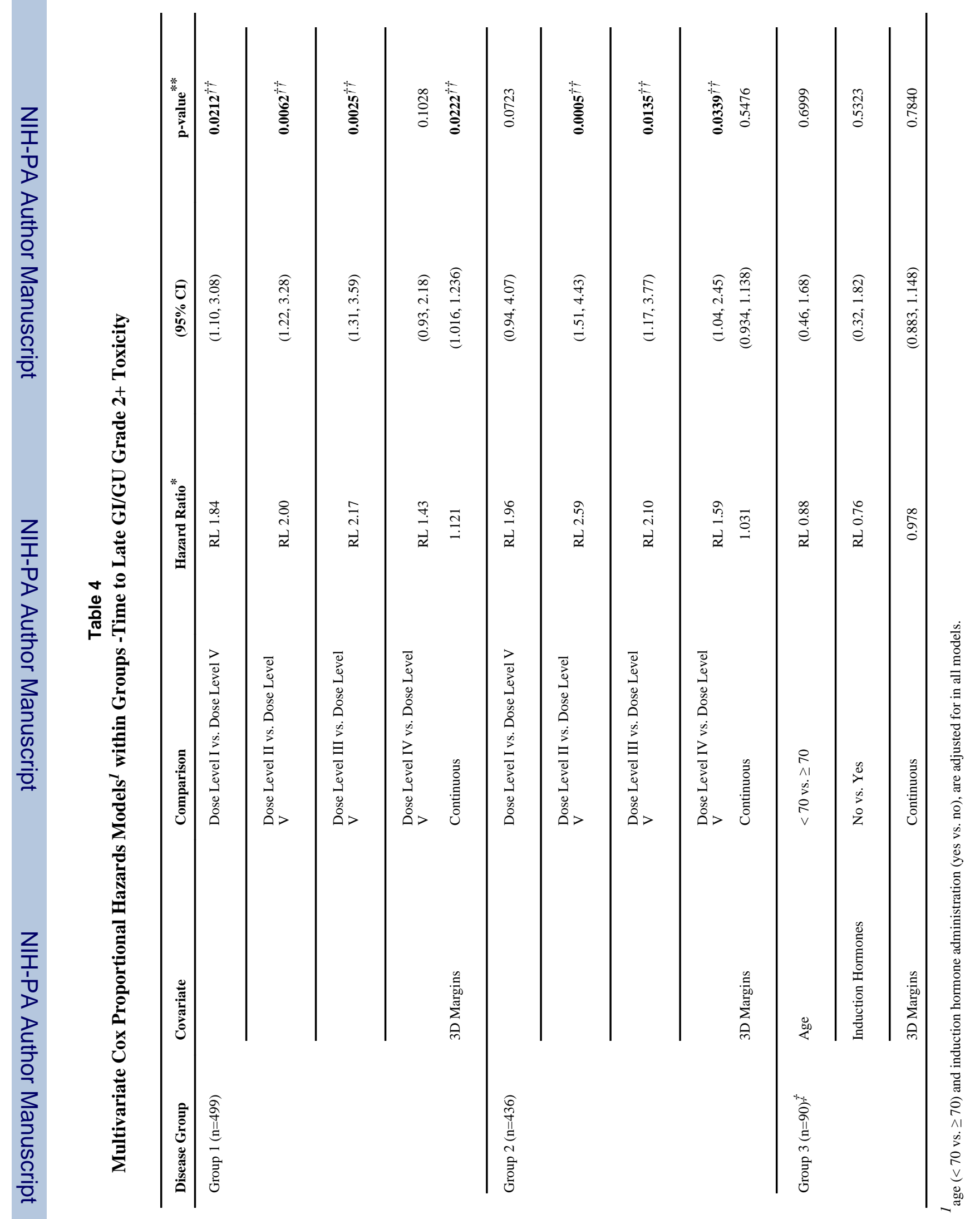




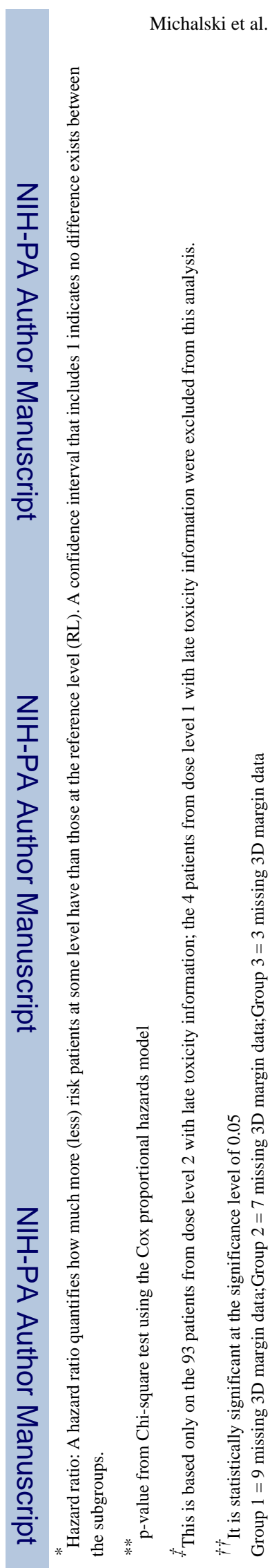

Int J Radiat Oncol Biol Phys. Author manuscript; available in PMC 2011 January 1. 